\title{
The Wooden Rod Foreign Body in the Urethra after Self-Dilatation of the Urethral Stricture: Case Report in the National Hospital of Ignace Deen Conakry (Guinea)
}

\author{
Demba Cisse*, Alpha Oumar Barry, Mamadou Diawo Bah, Housein Fofana, Mamadou Barry, \\ Thierno Mamadou Oury Diallo, Mamadou Bissiriou Bah, Daouda Kante, Boris Amougou, \\ Flora Fondjo Tchache, Ibrahima Bah, Abdoulaye Bobo Diallo, Oumar Raphiou Bah
}

Faculty of Health Science and Technic, Gamal Abdel Nasser University, Conakry, Guinea

Email: *adembacisse74@gmail.com

How to cite this paper: Cisse, D., Barry, A.O., Bah, M.D., Fofana, H., Barry, M., Diallo, T.M.O., Bah, M.B., Kante, D., Amougou, B., Tchache, F.F., Bah, I., Diallo, A.B. and Bah, O.R. (2021) The Wooden Rod Foreign Body in the Urethra after SelfDilatation of the Urethral Stricture: Case Report in the National Hospital of Ignace Deen Conakry (Guinea). Open Journal of Urology, 11, 313-316.

https://doi.org/10.4236/oju.2021.119029

Received: March 15, 2021

Accepted: September 6, 2021

Published: September 9, 2021

Copyright $\odot 2021$ by author(s) and Scientific Research Publishing Inc. This work is licensed under the Creative Commons Attribution International License (CC BY 4.0).

http://creativecommons.org/licenses/by/4.0/

\begin{abstract}
A foreign body in the urethra is the presence of an object in the urethra. They are often secondary, either to an erotic curiosity, $\hat{u}$ or to psychiatric disorders. The diagnosis remains clinically aided by imagery. Treatment is most often endoscopic, but in some cases the use of open surgery is necessary. We reported the case of an 80-year-old man with no history of behavioral disorders; a wooden rod was inserted into the urethra to empty his bladder. The care consisted of a meatoplasty under locoregional anesthesia. Upon discharge, the patient had a good urine flow.
\end{abstract}

\section{Keywords}

Foreign Body, Urethra, Meatoplasty

\section{Introduction}

Self-insertion of a foreign body into the urethra is a rare condition, it is often reported in the literature as isolated cases [1]. This condition may arise as a result of satisfaction of erotic curiosity, mental disorders, or rarely in the context of an attempt to evacuate urine during acute urinary retention [2]. Several types of foreign bodies have been described in the literature. The diagnosis is most often clinical and management is generally endoscopic [3].

Although it is more common in patients with mental disorders, it has also been described in people in full possession of all their mental abilities. We report 
through this clinical case a situation of self-insertion of a wooden rod in an 80 -year-old patient, presenting with meatal stenosis without any associated mental deficit. Through this case, we underscore the lack of information on urology in the general population and the socio-cultural considerations making urological pathologies taboo subjects.

\section{Observation}

We had an 80-year-old patient, retired, residing in Gbessia port 1 located in the region of Conakry, who was admitted with complaint of acute urinary retention secondary to urethral outlet obstruction occurring 2 hours after self-insertion of a wooden rod into the urethra. History taking revealed a relevant past history of purulent urethritis, hypertension and self-dilatation of the urethra using rigid objects (wooden rods, etc.). There was no psychiatry past history.

Physical examination revealed a satisfactory general condition, normal-colored skin and conjunctivae, $\mathrm{BP}=150 / 90 \mathrm{mmhg}$.

A palpable and mildly tender bladder globe, stenosis of the urethral meatus, induration along the anterior urethra from the navicular fossa to the root of the anterior third of the penis (Figure 1). The perineum was physically normal. On digital rectal examination, the prostate was slightly enlarged, smooth, elastic, painless and well limited.

An antero-posterior $\mathrm{x}$-ray of the pelvis with penile centering did not allow for visualization of the foreign body.

Urea and creatinin were normal.

The patient underwent urine drainage by transvesical catheter and meatoplasty associated with the removal of a wooden rod of about $4 \mathrm{~cm}$ (Figure 2). The urethral catheter was put to replace the cystostomy for one week, after the removal of the catheter the patient had a very good urine flow.

We reviewed the patient 6 months after meatoplasty with normal urine flow. Urine analysis and culture results were normal.

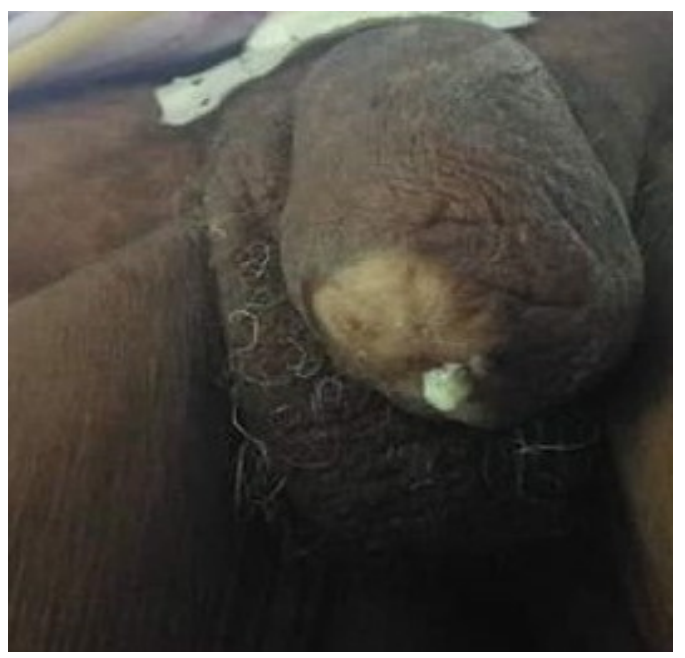

Figure 1. Stenosis of the meatus. 


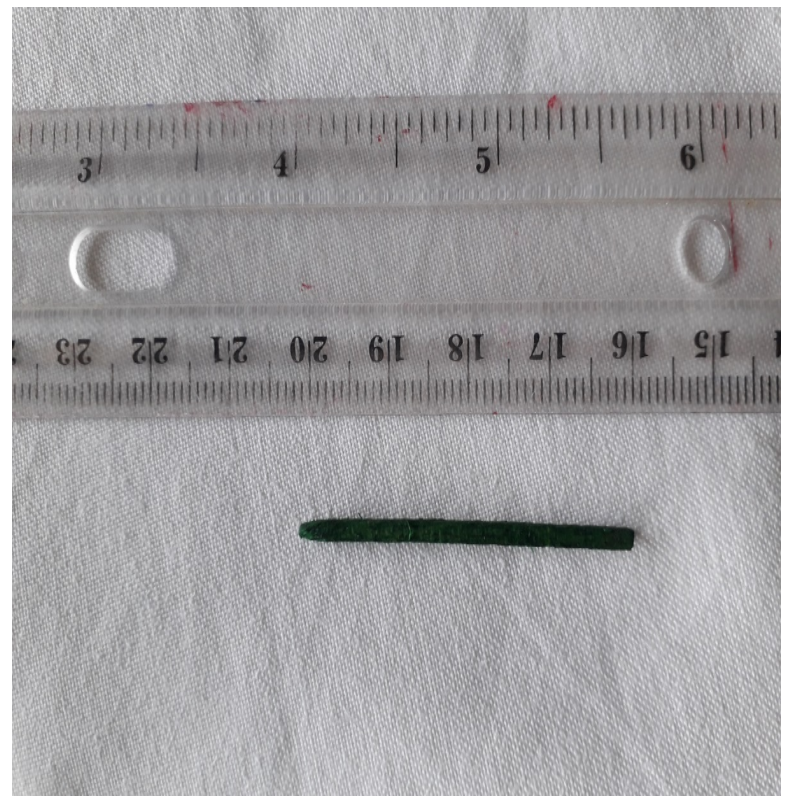

Figure 2. Foreign body.

\section{Discussion}

Most urinary tract foreign bodies are inserted during masturbation. This is however usually in the context of mental illness with self-aggressive impulsive acts [4].

Patients who are sometimes in full possession of their mental abilities use makeshift instruments for self-dilatation of the urethra. These instruments can remain or fragment in the urethra causing hemorrhagic, obstructive or infectious complications. Dysuria or urinary retention is the revealing symptoms of foreign bodies in the urethra [5]. The clinical and paraclinical diagnosis is based on history taking (notion of introduction of a foreign body into the urethra), physical examination (palpation of the foreign body along the urethra), radiography, computed tomography [3].

In our case, the diagnosis was purely clinical with palpation of the rod along the urethra. Antero-posterior pelvic X-ray didn't help for the diagnosis. Computed tomography was not done in this case.

Differential diagnosis with other urinary tract diseases can be difficult when patients do not admit that a foreign body has been self-inserted as could be the case in the event of mental illness or in the absence of a previous history of self-insertion foreign body [6]. Most foreign bodies from the urethra are removed by minimally invasive endoscopic techniques [1], and any manipulation or urethral catheterization should be prohibited until the exact type, shape, size, mobility and location of the object are determined. In some complex cases, such as that of our patient (anatomical abnormality of the associated urethra, calcified foreign body) [7] [8], surgery is certainly more invasive, but has the advantage of solving the problem without great morbidity. The foreign bodies are very varied, wooden rod as in the case of our patient, but also electric cables, tweezers, hair- 
pins, pushpins, pebbles, paper clips [6].

\section{Conclusion}

The self-insertion of foreign bodies into the urethra in patients in full possession of their mental faculties with urethral stenosis is carried out for the purpose of self-dilatation of the urethra. Treatment must systematically have two components, on one hand, the extraction of the foreign body and on the other hand the correction of the stenosis.

\section{Conflicts of Interest}

The authors declare no conflicts of interest regarding the publication of this paper.

\section{References}

[1] Ahsaini, M., Bounoual, M., Mellas, S., El Ammari, J., Tazi1, M.F., et al. (2018) Corps étranger intra urétral inhabituel chez un adolescent schizophrène: à propos d'un cas. Pan African Medical Journal, 31, Article No. 217. https://doi.org/10.11604/pamj.2018.31.217.15773

[2] Chouaib, A., Cabanis, P. and Billebaud, T. (2011) Corps étranger de l'urètre et dépression mélancolique, les implications diagnostiques aux urgences-à propos d'un cas clinique. Pan African Medical Journal, 9, Article No. 14. https://doi.org/10.4314/pamj.v9i1.71189

[3] El Bote, H., Hage, E. and Fares, R. (2017) Corps étranger inhabituel intra-urétral: à propos d'un cas. Pan African Medical Journal, 27, Article No. 58. https://doi.org/10.11604/pamj.2017.27.58.12644

[4] Hwang, E.C., Kim, J.S., Jung, S.I., et al. (2010) Delayed Diagnosis of an Intraurethral Foreign Body Causing Urosepsis and Penile Necrosis. Korean Journal of Urology, 51, 149-151. https://doi.org/10.4111/kju.2010.51.2.149

[5] Recasens Guinjuan, J.R., Flores González, J.J., Samsó Piñol, J.M. et al. (2002) VesicoUrethral Lithiasis Secondary to Foreign Body. Actas Urológicas Españolas, 26, 136-138. https://doi.org/10.1016/S0210-4806(02)72747-2

[6] Ndiaye, A., Niang, L., Kane, R., Diémé, E., Salif, N. and Ogougbemy, M. (2011)Un câblage inhabituel dans l'urètre. Basic and Clinical Andrology, 21, 263-265. https://doi.org/10.1007/s12610-011-0146-z

[7] Houlgatte, A. and Fournier, R. (2004) Les corps étrangers de l'urètre. Annales d Urologie, 38, 45-51. https://doi.org/10.1016/j.anuro.2004.02.001

[8] Moon, S.J., Kim, D.H., Chung, J.H., et al. (2010) Unusual Foreign Bodies in the Urinary Bladder and Urethra Due to Autoerotism. International Neurourology Journal, 14, 186-189. https://doi.org/10.5213/inj.2010.14.3.186 